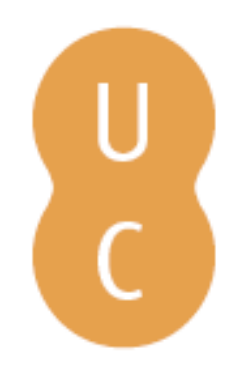

\title{
pommalina
}

\section{As energias renováveis em Portugal. A importância da energia hidroeléctrica e da energia eólica}

\author{
Autor(es): $\quad$ Saraiva, António \\ Publicado por: Imprensa da Universidade de Coimbra; Laboratório de Radioactividade \\ URL \\ persistente: URI:http://hdl.handle.net/10316.2/36317 \\ DOI: DOI:http://dx.doi.org/10.14195/978-989-26-1009-2_28 \\ Accessed : $\quad$ 26-Apr-2023 15:53:52
}

A navegação consulta e descarregamento dos títulos inseridos nas Bibliotecas Digitais UC Digitalis, UC Pombalina e UC Impactum, pressupõem a aceitação plena e sem reservas dos Termos e Condições de Uso destas Bibliotecas Digitais, disponíveis em https://digitalis.uc.pt/pt-pt/termos.

Conforme exposto nos referidos Termos e Condições de Uso, o descarregamento de títulos de acesso restrito requer uma licença válida de autorização devendo o utilizador aceder ao(s) documento(s) a partir de um endereço de IP da instituição detentora da supramencionada licença.

Ao utilizador é apenas permitido o descarregamento para uso pessoal, pelo que o emprego do(s) título(s) descarregado(s) para outro fim, designadamente comercial, carece de autorização do respetivo autor ou editor da obra.

Na medida em que todas as obras da UC Digitalis se encontram protegidas pelo Código do Direito de Autor e Direitos Conexos e demais legislação aplicável, toda a cópia, parcial ou total, deste documento, nos casos em que é legalmente admitida, deverá conter ou fazer-se acompanhar por este aviso.

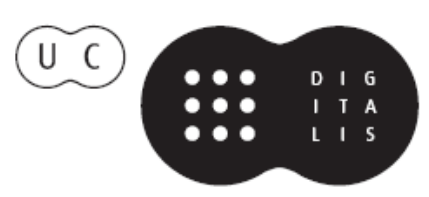




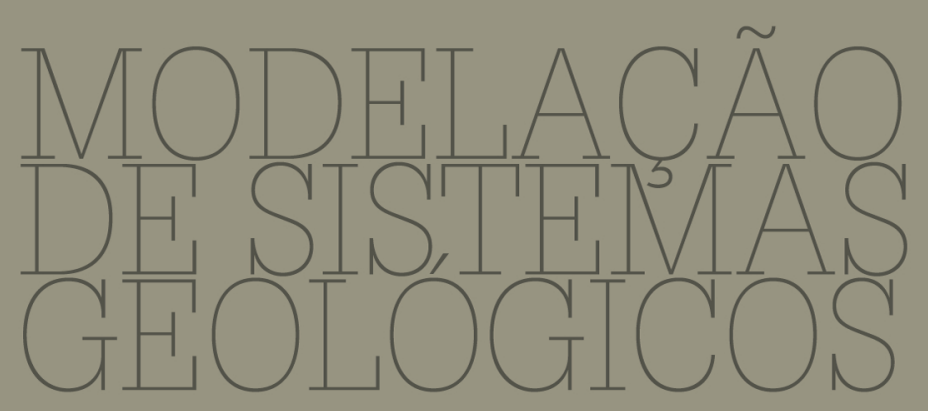

Homenagem ao Professor Doutor Manuel Maria Godinho

L.J.P.F. Neves, A.J.S.C. Pereira,

C.S.R. Gomes, L.C.G. Pereira,

A.O. TAVARES

IMPRENSA DA UNIVERSIDADE DE COIMBRA

CoImBra University Press 


\title{
MODELAÇÃO \\ DE SISTEMAS \\ GEOLÓGICOS
}

Homenagem ao Professor Manuel Maria Godinho

\section{As energias renováveis em Portugal. A importância da energia hidroeléctrica e da energia eólica}

\author{
António Saraiva ${ }^{1}$ \\ ${ }^{1}$ Departamento de Ciências da Terra da Universidade de Coimbra, PORTUGAL, asaraiva@dct.uc.pt
}

Palavras-chave: Energias renováveis, Energia hidroeléctrica, Energia eólica

\section{Resumo}

Apresenta-se uma análise da importância das energias renováveis em Portugal Continental e particularmente da energia hidroeléctrica e da energia eólica. A energia hidroeléctrica, especialmente a produzida nas grandes centrais, é essencialmente produzida nas horas mais nobres do diagrama de consumos. A energia eólica que é volátil e intermitente, pode ter produções muito variáveis ao longo do dia. Na generalidade das situações a produção de energia eólica é mais intensa durante a noite do que durante o dia, o que coloca dificuldades à gestão da rede eléctrica, devido à dificuldade em descontinuar as centrais térmicas. Assim, o seu adequado aproveitamento só pode ser feito com recurso a aproveitamentos hidroeléctricos em regime de albufeira e com capacidade de bombagem hidroeléctrica instalada. A potência hidroeléctrica instalada, que teve um peso de $81 \%$ na década de 60 , passou para $29 \%$ em 2009. Em contraponto a potência eólica instalada passou de $76 \mathrm{MW}$, em 2000, para 3841 MW em Setembro de 2010. Portugal, na sequência de directivas da União Europeia, deveria ter no ano de 2010 uma taxa de cobertura de $39 \%$ de fontes de energia renováveis (FER) relativamente à energia bruta produzida

Key-words: Renewable energy, Hydropower energy, Wind energy

\begin{abstract}
Hydropower and wind power are important in Portugal. Hydropower, in large power plants, is mainly produced in the finest hours of the diagram of consumption. Wind power is intermittent and volatile, and may have highly variable yields throughout the day. In general the production of wind energy is more intense at night than during the day, which poses difficulties for the management of the electric grid, due to difficulty in discontinuing the thermal power plants. Thus, their proper use can only be done using hydropower plants with pumping water capacity installed. The hydroelectric power installed, which had a weight of $81 \%$ in 1960 , fall to $29 \%$ in 2009 . In contrast the wind power installed rose from $76 \mathrm{MW}$ in 2000 to $3841 \mathrm{MW}$ in September 2010. Portugal, following the UE directives, should have in 2010 a coverage rate of $39 \%$ from renewable energy sources (RES) for the gross energy produced.
\end{abstract}




\section{Introdução}

A produção de energia eléctrica a partir de fontes de energia renováveis (FER) tem sido ampla e intensamente desenvolvida em Portugal, particularmente ao nível da energia eólica. A União Europeia, através das directivas definiu metas para os vários países integrantes ao nível da percentagem de cobertura das FER, apontando-se que em 2010 Portugal deveria ter uma cobertura de $39 \%$ relativamente à energia bruta produzida. No fim do ano de 2009 o parque electroprodutor compreendia uma potência instalada de $11268 \mathrm{MW}$ em centrais pertencentes aos Produtores em Regime Ordinário (PRO) e de $5128 \mathrm{MW}$ em centrais pertencentes aos Produtores em Regime Especial (PRE). Em Portugal, o potencial hidroeléctrico explorado é de $46 \%$, o que contrasta, por exemplo, com os $96 \%$ na Alemanha e os 95\% na França e na Itália.

\section{As Energias Renováveis}

O poder político executivo em Outubro de 2003, estabeleceu as metas a alcançar para as diferentes formas de produção de energia na sequência da directiva da União Europeia. Mais recentemente, o MEI (Tabela 1) redefiniu essas metas que se tornaram mais ambiciosas na sequência da aprovação do Plano Nacional de Barragens com Elevado Potencial Hidroeléctrico (PNBEPH) que prevê que o potencial hidroeléctrico aproveitado passe dos actuais $46 \%$ para os $70 \%$ em 2020 e que a potência eólica instalada atinja os $5700 \mathrm{MW}$ (COBA, PROCESL, 2007). No entanto, e apesar do forte investimento na instalação de novos parques eólicos, ainda falta instalar, para se alcançarem as metas definidas, $2292 \mathrm{MW}$ de potência eólica.

Mais recentemente, em Setembro de 2010, foi estabelecido o programa Estratégia Nacional de Energia 2020 (ENE 2020) em que se preconizam novas metas a atingir ao nível das FER, a saber (Tabela 2).

\section{A Complementaridade Hídrica-Eólica}

O potencial hidroeléctrico por explorar em condições técnicas e económicas é da ordem dos 5,2 TW. A importância dos aproveitamentos hidroeléctricos na produção de energia eléctrica atingiu um máximo em 1960 com um valor de $81 \%$ e de então para cá tem vindo progressivamente 
Tabela 1. Metas indicativas para as fontes de energia renováveis

\begin{tabular}{|c|c|c|}
\hline Referência & Metas Anteriores & Novas Metas (2007-2010) \\
\hline $\begin{array}{c}\text { Produção de electricidade } \\
\text { com base energias } \\
\text { renováveis }\end{array}$ & $39 \%$ do consumo bruto & $45 \%$ do consumo bruto \\
\hline Energia hidroeléctrica & $\begin{array}{c}46 \% \text { do potencial } \\
5000 \mathrm{MW} \text { em } 2010\end{array}$ & $\begin{array}{c}7000 \mathrm{MW} \text { em 2020, 70 \% } \\
\text { do potencial } \\
(5575 \mathrm{MW} \text { em 2010) }\end{array}$ \\
\hline Energia eólica & $3750 \mathrm{MW}$ & $\begin{array}{c}5100 \mathrm{MW} \text { em novas } \\
\text { istalações + 600 MW por } \\
\text { upgrade do equipamento } \\
\text { em 2010 }\end{array}$ \\
\hline Biomassa & $100 \mathrm{MW}$ & $150 \mathrm{MW}$ \\
\hline Solar & $50 \mathrm{MW}$ & $150 \mathrm{MW}$ \\
\hline Ondas & $50 \mathrm{MW}$ & $250 \mathrm{MW}$ em zonas piloto \\
\hline Biogás & $50 \mathrm{MW}$ & $100 \mathrm{MW}$ \\
\hline $\begin{array}{c}\text { Biocombustíveis } \\
\text { (transportes rodoviários) }\end{array}$ & $5,75 \%$ & 50000 sistemas \\
\hline Micro-geração & -- &
\end{tabular}

Tabela 2. Metas indicativas para as fontes de energia renováveis

\begin{tabular}{|c|c|}
\hline Referência & ENE 2020 (RCM 29/2010) \\
\hline Consumo de energia final & $31 \%$ \\
\hline Energia hidroeléctrica & $8600 \mathrm{MW}$ até 2020 \\
\hline Mini-hídricas & Mais 250 MW \\
\hline Energia eólica & $+2000 \mathrm{MW}$ até 2012 (já atribuída) \\
& $+400 \mathrm{MW}$ sobreequipamento de parques \\
& $\begin{array}{c}\text { existentes } \\
\end{array}$ \\
\hline Biomassa & $+3000 \mathrm{MW}$ (a atribuir por concurso \\
\hline Solar & $+1500 \mathrm{MW}$ \\
\hline Ondas & $+250 \mathrm{MW}$ \\
\hline Geotermia & $+250 \mathrm{MW}$ \\
\hline
\end{tabular}

a diminuir e, em 2009, ficou pelos $29 \%$ (Figura 1). A par deste facto, verificou-se que de um modo vincado a partir do ano de 2003, ocorreu um grande incremento na potência eólica instalada que passou de $253 \mathrm{MW}$ para 3841 MW em Setembro de 2010. Nas últimas décadas a construção de novos aproveitamentos hidroeléctricos foi reduzida, tendo sido construídos os aproveitamentos do Alto Lindoso, que entrou em funcionamento no ano de 1994, com uma potência instalada de $630 \mathrm{MW}$ nos dois grupos, e o de 


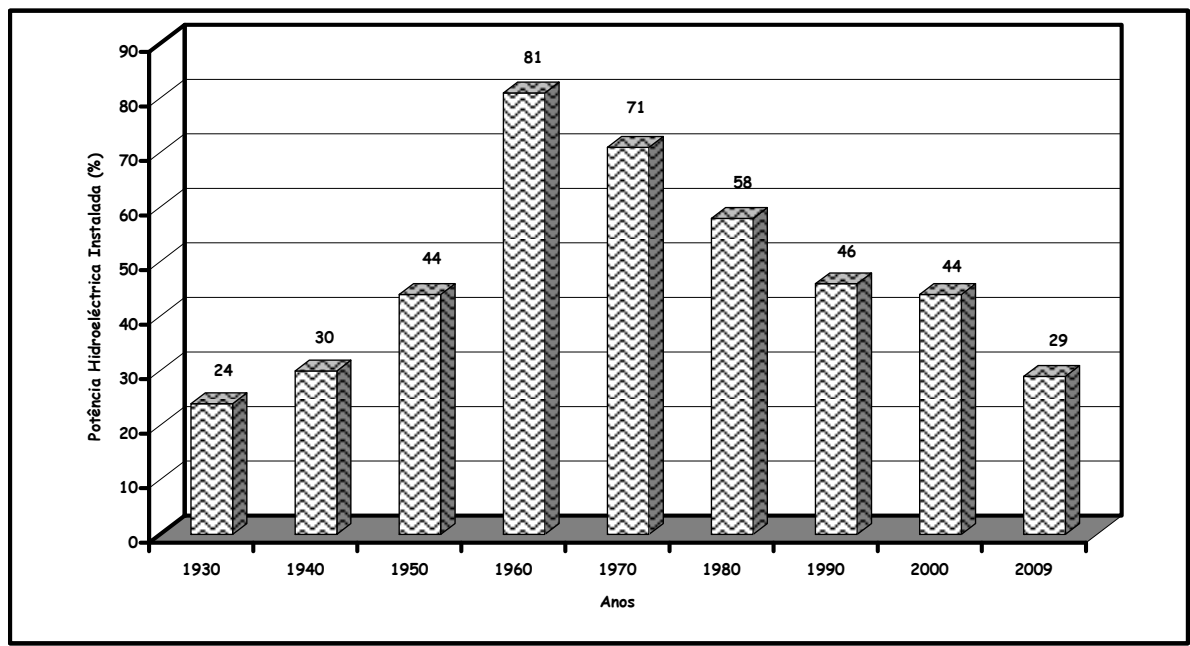

Figura 1. Peso relativo da potência hidroeléctrica instalada relativamente à potência total (dados de Vasconcelos, 2010).

Alqueva com uma potência instalada de 260 MW que entrou em funcionamento em 2004 e o de Frades (reforço de potência designado por Venda Nova II durante a fase de obras) com uma potência de 191,6 MW e que foi inaugurado no ano de 2007. Estes dois últimos centros electroprodutores estão equipados com grupos reversíveis.

$\mathrm{O}$ grande incremento verificado na instalação de potência eólica (Figura 2) coloca problemas significativos à gestão da rede de transporte. A produção eólica é muito volátil e intermitente conforme o evidenciam os diagramas de produção eólica disponibilizados pela REN. Por outro lado, a energia eólica é uma energia que não está submetida a instruções de despacho como acontece, por exemplo, com a hidroeléctrica ou a térmica. Tal implica que seja necessário dispor de equipamentos geradores de reserva capazes de rapidamente poderem entrar, e sair, de serviço, quer em regime de produção, quer em regime de bombagem hidroeléctrica. Tal poderá permitir fazer um adequado aproveitamento dos excedentes de energia existente na rede.

A volatilidade e a intermitência da energia eólica podem ser exemplificadas pelas situações referidas a seguir e pelos dados apresentados na tabela 3.

Em 22 de Setembro de 2008 a energia eólica produzida satisfez 0,7 \% do consumo de energia eléctrica, em 28 de Março de 200937 \%. Em 25 de Março de 2010, a energia eólica alcançou a maior quota instantânea do consumo com um valor de $63 \%$ às $2 \mathrm{~h} 45 \mathrm{~min}$. (REN, 2010). 


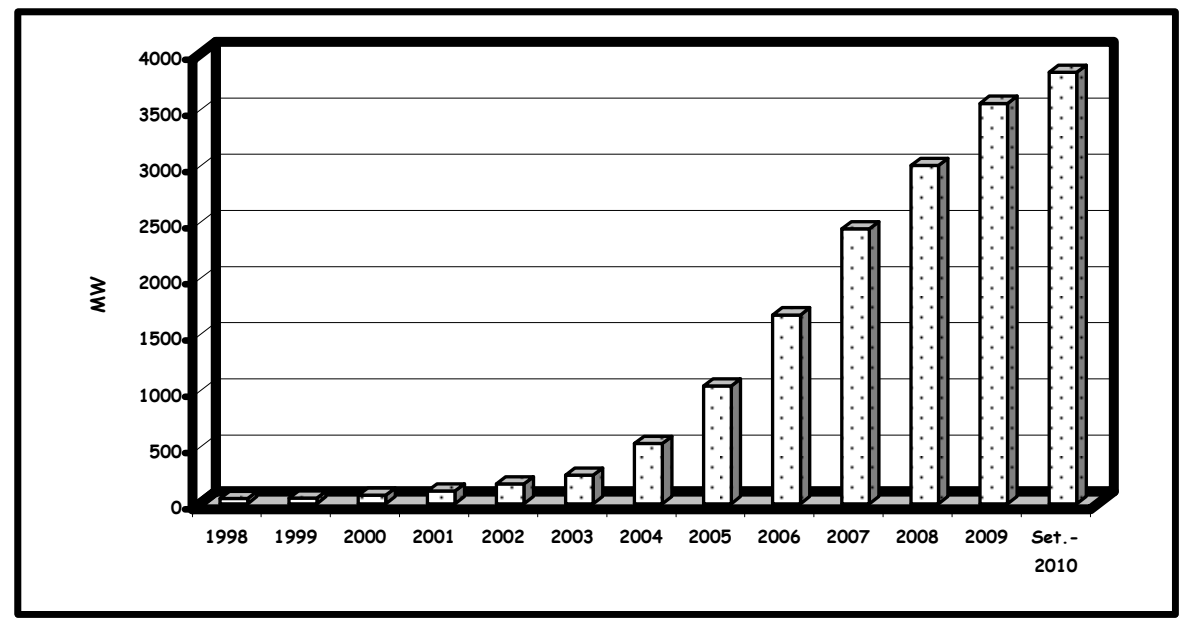

Figura 2. Variação da potência eólica instalada (Dados da DGEG, 2010).

Tabela 3. Alguns indicadores relativos à energia eólica e à bombagem hidroeléctrica (dados da REN, 2007, 2008, 2009 e 2010).

\begin{tabular}{|c|c|c|c|c|}
\hline & 2007 & 2008 & 2009 & $\begin{array}{l}2010-1^{\circ} \\
\text { Sem. }\end{array}$ \\
\hline $\begin{array}{l}\text { Ponta máxima rede pública } \\
\text { (MW) }\end{array}$ & 9110 & 8973 & 9217 & 9403 \\
\hline Potência eólica máxima (MW) & 1693 & 2197 & 2856 & 3031 \\
\hline $\begin{array}{l}\text { Máxima produção eólica diária } \\
\text { (GWh) }\end{array}$ & 37 & 45 & 64 & 63 \\
\hline Maior consumo nacional (\%) & 21 & 32 & 49 & 43 \\
\hline $\begin{array}{l}\text { Potência eólica instantânea } \\
\text { máxima }(\%)\end{array}$ & 96 & 48 & 69 & 63 \\
\hline Bombagem hidroeléctrica (GWh) & 541 & 639 & 929 & 191 \\
\hline
\end{tabular}

Para além destes factos há a assinalar que podem ocorrer perdas significativas de potência em intervalos de tempo muito reduzidos, como é evidenciado nos diagramas relativos à produção eólica referente ao dia 15 de Novembro de 2009. Neste dia (REN, 2009), ocorreram perdas de potência superiores a $590 \mathrm{MW}$ e a $500 \mathrm{MW}$ entre as $11 \mathrm{~h}-11 \mathrm{~h} 15 \mathrm{~min}$. e as 14h 15 min. - 14h 30 min, respectivamente, e ganhos superiores a $400 \mathrm{MW}$ e a $360 \mathrm{MW}$ entre as $11 \mathrm{~h} 15 \mathrm{~min}-11 \mathrm{~h} 30 \mathrm{~min}$ e as $14 \mathrm{~h} 30 \mathrm{~min}-14 \mathrm{~h} 45 \mathrm{~min}$. As quebras ou incrementos de potência registados são muito significativos. A título de exemplo refira-se que os centros electroprodutores, com maior 
potência, instalados em Portugal são a central termoeléctrica de Sines (central a carvão), que está equipada com quatro grupos geradores com uma potência total de $1256 \mathrm{MW}$ e a central termoeléctrica do Ribatejo (central de ciclo combinado a gás natural) equipada com três grupos geradores com uma potência de $1200 \mathrm{MW}$. Estes acontecimentos obrigam à mobilização de equipamentos de reserva capazes de entrarem em produção muito rapidamente.

As centrais hidroeléctricas, em regime de albufeira, podem entrar e sair da rede muito rapidamente (poucos minutos), o que lhes confere uma grande flexibilidade para a gestão do sistema e a produzirem energia nas horas "mais nobres" em que o custo da energia eléctrica na produção é significativamente mais elevado do que nas designadas horas de vazio. A bombagem hidroeléctrica permite fazer bombagem de jusante para montante, quando existem excedentes de energia na rede (originada pela produção térmica durante a noite ou por excesso de energia eólica), para posterior turbinamento nas designadas horas de ponta em que o custo da energia produzida é significativamente mais elevado.

$O$ facto do incremento na produção eólica não estar a ser acompanhado por um aumento na capacidade de bombagem, pode originar dificuldades acrescidas. No decorrer do ano de 2010, o excesso de produção de energia a partir de fontes de energia renováveis levou à exportação de energia a custo zero em períodos significativos do dia como aconteceu, por exemplo, nos primeiros dias de Janeiro de 2010. No sentido de evitar que num futuro, a médio prazo, estes acontecimentos voltem a ocorrer com a mesma intensidade, a generalidade dos aproveitamentos hidroeléctricos em construção, e a construir no âmbito do PNBEPH, ficarão equipados com grupos reversíveis no sentido de permitirem uma gestão mais adequada da energia, quer nas horas de vazio, quer nas horas de ponta (tabela 4).

De modo a incentivar a produção de energia eléctrica a partir de fontes renováveis, particularmente com base na mini-hídrica, o Governo da República Portuguesa abriu em Novembro de 2010 um procedimento concursal conducente ao licenciamento de aproveitamentos hidroeléctricos com uma potência máxima a instalar de até $20 \mathrm{MW}$. As concessões serão atribuídas por 45 anos e aos produtores será paga, durante 25 anos, uma tarifa média indicativa de $€ 95 / \mathrm{MW}$. Refira-se que os preços marginais para Portugal, praticados no OMEL, variaram no dia 5 de Janeiro de 2010 entre $€ 1,03$ / MWh e $€ 57,86$ / MWh, no dia 1 de Novembro de 2010 entre $€ 0,10 / \mathrm{MWh}$ e $€ 58,13 / \mathrm{MWh}$, no dia 30 de Novembro de 2010 entre $€ 32,90$ / MWh e $€ 74,51 / \mathrm{MWh}$, enquanto que no dia 5 de Dezembro de 2010 os preços oscilaram entre $€ 30,92$ / MWh e $€ 54,0$ / MWh. 
Tabela 4. Designação e potência dos A. H. a construir e em construção (INAG).

\begin{tabular}{|l|l|c|c|}
\hline Aproveitamento & Adjudicatário & Potência a Instalar (MW) & Reversibilidade \\
\hline & & A construir & \\
\hline Gouvães & Iberdrola & 660 & Sim \\
\hline Padroselos $\left(^{*}\right)$ & Iberdrola & 230 & Sim \\
\hline Daivões & Iberdrola & 118 & Não \\
\hline Alto Tâmega & Iberdrola & 127 & Não \\
\hline Girabolhos & Endesa & $354,8(2$ escalões $)$ & Sim \\
\hline Foz-Tua & EDP & 323,6 & Sim \\
\hline Fridão & EDP & 256 & Não \\
\hline Alvito & EDP & 136 & Sim \\
\hline \multicolumn{5}{|l|}{} & Em construção & Sim \\
\hline Baixo Sabor & EDP & $140+30(2$ escalões $)$ & Sim \\
\hline Ribeiradio-Ermida & Greenvouga & $72+6,6(2$ escalões $)$ & . \\
\hline
\end{tabular}

(*) - Este aproveitamento não será construído na sequência da emissão da correspondente Declaração de Impacte Ambiental (DIA).

\section{Considerações finais}

A forte implementação da energia eólica representa um contributo para a produção de energia eléctrica a partir das FER e, por via disso, permitir uma acentuada redução das emissões de $\mathrm{CO}_{2}$ para a atmosfera. No entanto, dada a sua volatilidade, intermitência e o facto de ser uma energia não despachável, a mesma só poderá ser utilizada cabalmente, e de um modo racional, quando conjugada com os aproveitamentos hidroeléctricos equipados com grupos reversíveis (turbina-bomba) de modo a possibilitar que em períodos de excesso de energia na rede se recorra à bombagem hidroeléctrica.

\section{Bibliografia}

COBA, PROCESL (2007) - Programa Nacional de Barragens com Elevado Potencial Hidroeléctrico (PNBEPH). Memória, 183 pp.

DGEG (2010) - Renováveis. Estatísticas Rápidas. Agosto/Setembro, nº 66/67, 22 pp. Direcção Geral de Energia e Geologia.

INAG. http://pnbeph.inag.pt/np4/p/projectos (consultada em 20/10/2010). 
REN (2007, 2008, 2009 e 2010) - Estatísticas Diárias e Mensais dos Consumos de Energia Eléctrica. Redes Energéticas Nacionais, S. A.

Resolução do Conselho de Ministros 29/2010 (2010) - Diário da República, 1ª Série, de 10 de Setembro de 2010.

Vasconcelos, J. (2010) - O futuro das Políticas Energéticas. CIAHP2010, Porto, 15-33. 